\title{
PESQUISA CENTRÍPETA E OPERACIONAL DE FOCOS DE TUBERCULOSE A PARTIR DO LEVANTAMENTO TUBERCULINICO
}

\author{
* Daisy Leslie Steagall-Gomes \\ ** Iranilde José Messias-Mendes \\ *** Maria Cecilia Puntel de Almeida \\ **** Antonio Ruffino-Netto
}

RBEn/13

STEAGALL-GOMES D.L. e colaboradores - Pesquisa centrípeta e operacional de focos de tuberculose a partir do levantamento tuberculínico. Rev. Bras. Ene.; DF, 29 : 106114, 1976.

\section{INTRODUÇAOO}

A Divisão Nacional de Tuberculose recomendou que antes da implantação de programas de vacinação com BCG intradérmíco, fosse feito um estudo operacional da aceitação e/ou complicação da referida vacina. (LIMA, GERHARDT \& CASTRO, 1974').

Atendendo a esta recomendação, foi levado a efeito um estudo operacional da vacinação pelo BCG intradérmico na cidade de Ribeirão Preto, nos escolares da $1 .^{\text {a }}$ série do $10^{\circ}$ grau (Puntel de Almeida \& Col., 1975).

No cadastramento prévio, feito através do teste tuberculínico, selecionou-se o grupo dos negativos que foram enca- minhados para a vacinação; o grupo dos reatores positivos foi motivo do presente estudo a que nos propusemos com os seguintes objetivos:

1. Estudar o aspecto operacional do programa de controle da infecção tuberculosa, nestes escolares, pelo Centro de Saúde;

2. Efetuar uma pesquisa centrípeta do foco de infecção, a partir das crianças reatoras.

\section{MATERIAL E METODO}

\section{População}

Em 2.535 escolares de Ribeirão Preto, submetidos ao teste tuberculínico, obte-

- Professor Colaborador da Escola de Enfermagem de Ribeirāo Preto - USP.

* Auxiliar de Ensino da Escola de Enfermagem de Ribeirão Preto - USP.

*** Professor Assistente da Fiscola de Enfermagem de Ribeirão Preto - USP.

*** Professor Livre-Docente ua Faculdade de Medicina de Ribeiräo Preto - USP. 
STEAGALL-GOMES, D.L. e colaboradores - Pesquisa centrípeta e operacional de focos de tuberculose a partir do levantamento tuberculínico. Rev. Bras. Enf.; DF, 29 : 106114, 1976.

ve-se a leitura em 2.420, sendo 2.208 resultados negativos (que foram encaminhados para vacinação pelo BCG intradérmico (Puntel de Almeida \& Col., 1975) e 212 resultados positivos. Estes 212 escolares reatores positivos (induração maior ou igual a $5 \mathrm{~mm}$ de diâmetro) constituíram o material do presente trabalho.

\section{Prova Tuberculínica}

A tuberculina utilizada fol o PPD-RT 23, Tween 80, 2TU, aplicada e lida após 72 horas, por enfermeiras de Saúde Pública previamente padronizadas.

Este levantamento fol feito em setembro de 1972.

\section{Procedimentos}

Todos os reatores positivos, por ocasiāo da leitura, foram orientados pela enfermagem de Saúde Pública, para que procurassem o Centro de Saúde local onde receberiam o tratamento adequado (cada escolar recebia para isso uma ficha contendo sua identificação, o resultado da prova tuberculínica e o nome do funcionário do Centro de Saúde que deveria procurar para o seu encaminhamento).

Na semana seguinte, após a leitura, objetivando dar um maior reforço ao encaminhamento, assim como levantar os focos de tuberculose, fol efetuada a visitação domiciliária destas crianças.

Dos 212 escolares, conseguiu-se levar a bom termo a visitação em 169 domicílios, sendo que em 43 não fol possível localizar o endereço e/ou seus residentes.

Durante a visitação foi preenchido um questionário (pré-estabelecido) visando evidenciar o foco contagioso de tuberculose.

Através do arquivo da seção de quimioprofilaxia e quimioterapia da área de
Tisiologia do referido Centro, foi possivel enumerar: quantos escolares compareceram à unidade; destes, quantos foram encaminhados para tratamento direto, ou exames complementares, ou controle periódico, bem como outras condutas indicadas e a evolução do seguimento até à alta ou abandono.

\section{RESULTADOS E DISCUSSĀO}

Na Tabela I é apresentada a distribuição dos escolares reatores à prova tuberculínica, segundo o grupo etário, sexo e cor. Observa-se que a quase totalidade dos reatores está no grupo etário de 6 a 9 anos, o que é perfeitamente esperado, uma vez que o critério de seleção dos escolares para o programa de vacinação foi escolher alunos da $1 .^{\text {a }}$ série do $1 .^{\circ}$ grau.

A Tabela 2 mostra a distribuição dos escolares segundo o recebimento das visitas domiciliares feitas pela enfermagem de Saúde Pública e o comparecimento ao Centro de Saúde local. Observa-se que $81,6 \%$ dos que receberam visita, procuraram o Centro de Saúde, enquanto que o grupo não visitado, apenas $34,9 \%$ o fizeram/ Esta diferença de aproximadamente $50 \%$ no comparecimento entre o grupo visitado e 0 não visitado, acreditamos que possa ser atribuída ao trabalho de orientação efetuado pela enfermagem de Saúde Pública, durante a visita, evidenciando-se assim uma grande eficácia neste tipo de atividade. Evidentemente, o reforço em nivel de domicílio é muito importante em termos de educação para a saúde, como seria de se esperar. Acreditamos que os $34,9 \%$ que compareceram ao Centro de Saúde, independentemente de não terem sido visitados, assim o fizeram talvez sensibilizados apenas com a orientação inicial recebida ao nível da escola, durante a leitura do seu teste. Lembramos que todos os escolares, assim como os 
pais e professores, foram orientados quanto a fatores ligados à tuberculose durante a preparação para o cadastramento tuberculínico e vacinação, como já foi descrito em publicação prévia (Puntel de Almeida \& Col., 1975).

Na Tabela 3 é apresentada a distribuição dos escolares, cujos domicílios foram visitados, segundo encaminhamento recebido no Centro de Saúde e a evolução durante o controle. De um total de 143 escolares que procuraram o Centro de Saúde, em 36 casos o foco foi detectado ou já era conhecido; em 107 foco continuava desconhecido. Quanto ao grupo encaminhado para tratamento direto (10 casos), observamos que 3 abandonaram e 7 chegaram à alta médica, representando respectivamente 2,1 e $4,9 \%$ do total dos 143. Quanto ao grupo encaminhado para exames complementares (Rô e/ou Rx) 72 (50,3\% em relação aos 143) não voltaram ao Centro de Saúde; $27(6+21)$ abandonaram a quimioprofilaxia ou o controle, isto é, $18,9 \% ; 25(17+8)$ chegaram a receber alta da quimioprifilaxia ou do controle, ou seja $17,5 \%$. Do grupo encaminhado para controle periódico sem medicação, 3 não voltaram $(2,1 \%)$ e 2 voltaram, sendo que $1(0,7 \%)$ abandonou durante o controle e $1(0,7 \%)$ chegou à alta médica. Perdeu-se o controle de 4 crianças devido a condutas de tratamento, nāo definidos (3 casos) e transferência para outra cidade (1 caso).

Observamos assim que, operacionalmente falando, dos efetivamente encaminhados ao Centro de Saúde, ou seja 139 (são os 143 menos os 4 perdidos do seguimento), apenas 33 chegaram a receber alta médica ,ou seja 33

$$
\left(\frac{33}{139} \times 100=23,7 \%\right) \text { dos encaminha- }
$$

dos. Acreditamos ser uma porcentagem muito baixa que chega ao final de uma orientação estabelecida, acrescidas dos fatos de que o grupo recebia visita domiciliária com reforço para educação em saúde, e de se tratar de um Centro de Saúde Regional de Nível 1 em cujas atividades se deveria esperar maior rendimento.

Na Tabela 4 é apresentada a distribuição dos escolares (cujos domicílios não foram visitados) segundo o encaminhamento e evolução do seguimento. De um total de 15 escolares nestas circunstâncias, $1(6,6 \%)$ abandonou 0 seguimento (após ter sido encaminhado para tratamento direto sem exames complementares). De 14 encaminhados para exames complementares, $9 \quad \mathbf{6 0 0 \%}$ em relação aos 15) não voltaram; e 5 $(4+1)$ tiveram alta da quimioprofilaxia ou do controle.

Assim, em conjunto de $158(143+15)$ que chegaram ao Centro de Saúde, 154 efetivamente receberam encaminhamento, sendo que de 4 foi perdido 0 contato. Dos 154, 116 abandonaram o seguimento em qualquer etapa e apenas

$$
38\left(\frac{38}{154} \times 100=24,6 \%\right) \text { chegaram à }
$$

alta médica, evidenciando como anteriormente exposto a baixa eficácia e eficiência do programa de controle de infecção tuberculosa levada a efeito pelo referido Centro de Saúde.

Quanto à pesquisa centrípeta objetivando localizar os focos de tuberculose, observamos que de 169 domicílios visitados, em $38\left(\frac{38}{169} \times 100=22,4 \%\right)$ casos conseguimos evidenciar o foco, assim como discriminá-lo (dados estes que são apresentados na tabela 5). Nesta tabela observamos que dos 38 casos, em 24 trata-se de focos coabitantes com o escolar infectado. Nota-se ainda que os pais ocupam o primeiro lugar em freqüência como fonte de infecção para o escolar, a seguir os tios, irmãos e outros. 
STEAGALL-GOMES, D.L. e colaboradores - Pesquisa centripeta e operacional de focos de tuberculose a partir do levantamento tuberculínico. Rev. Bras. Enf.; DF, 29 : 106$114,1976$.

Em 14 focos não coabitantes com o infectado, observamos que tios e vizinhos representam pelo menos neste grupo, as maiores fontes de infecção.

Como sabemos, a porcentagem de detecção de focos de infecção tuberculosa é inversamente proporcional à idade da pessoa infectada. Dado nossa população infectada estar no grupo etário de 6 a 15 anos (predominantemente no grupo 16 - 9 anos) não é de se estranhar muito a baixa porcentagem de localização de focos que encontramos $(22,4 \%)$, embora esteja bem aquém do que gostaríamos ou desejaríamos que fosse.

A medida que a criança amplia seu contato e convívio social, naturalmente aumenta sua probabilidade de infecção no meio extra-domiciliar (tais como escolas, clubes, etc.).

Os dados desta pesquisa centrípeta, embora não seja uma amostra representativa de todos os escolares da cidade, constitui, contudo, um universo de 2.535 escolares submetidos ao teste.

Estes resultados parecem evidenciar 0 grande ou o importante papel que especificamente o pai (intra-domiciliarmente) e os tios e vizinhos (extra-domiciliarmente) representam como foco de infecção. Seria esta conclusão válida em uma amostra representativa de toda a cidade ou em outras regiōes? Sugerimos que um estudo específico seja feito posteriormente neste sentido.

\section{CONCLUSAO}

Concluímos portanto que é baixa a eficácia e a eficiência dos programas de controle de tuberculose levados a efeito entre os escolares infectados que procuraram o Centro de Saúde de Ribeirão Preto.

Quanto à pesquisa centrípeta, conseguimos localizar $22,4 \%$ dos focos de tuberculose na população infectada no grupo etário de 6 a 15 anos.

\section{RESUMO}

A partir de um levantamento do índice de infecção pelo bacilo da tuberculose, através da prova tuberculínica entre os escolares de Ribeirão Preto, foram submetidos ao teste 2.535 (100\%) escolares, sendo lidos $2.420(95,4 \%)$ testes, resultando negativos $2.208(91,2 \%)$ e positivos $212(8,76 \%)$.

Os reatores positivos (com induração maior ou igual a $5 \mathrm{~mm}$ ) foram encaminhados para o Centro de Saúde local e reforçado o encaminhamento através de visitação domiciliária.

Destes, $158(74,5 \%)$ compareceram ao Centro de Saúde onde foram encaminhados para atendimento médico e entraram na rotina do tratamento.

Apenas $38(24,0 \%)$ chegaram à alta médica.

A pesquisa centrípeta para levantamento de foco, através da visitação domiciliária, evidenciou a presença de 38 $(22,4 \%)$ casos de tuberculose conhecidos.

\section{BIBLIOGRAFIA}

LMMA, L. L.; GERHARDT, G. \& CASTRO, I. B. - "Ensaio de vacinaçāo intradérmica em escolares das capitais brasileiras". Rev. Div. Nac. Tub., 18:286, 1974.

PUNTEL DE ALMEIDA, M. C.; STEAGALLGOMES, D. L.; RUFFINO-NETTO, A.; ARANTES, G. R.; NASSAR, J.; PESSINI DE OLIVEIRA, M. H. \& MES-
SIAS - MENDES, I. J. - “Vacinaçāo $B C G$ intradérmico em escolares de Ribeirāo Preto. Apresentado no I Congresso Brasileiro de Pneumologia e Tisiologia; II Jornada Internacional de Pneumologia; XVII Congresso Nacional de Tisiologia e Doenças Respiratorias". Brasilia - DF, 14 a 18 de outubro de 1975. 
STEAGALL-GOMES, D.L. e colaboradores - Pesquisa centrípeta e operacional de focos de tuberculose a partir do levantamento tuberculínico. Rev. Bras. Ene.; DF, 29 : 106$114,1976$.

淧

क

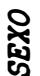

है

త্ড

$\frac{1}{2}$

ป⿻

ณิ

Е 웜

ธ

옹 옹

달

है

옹

ำ

है

S

ర్ర

ติ

8

논

芯

คิ

趈

0

$r$

sิ

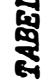

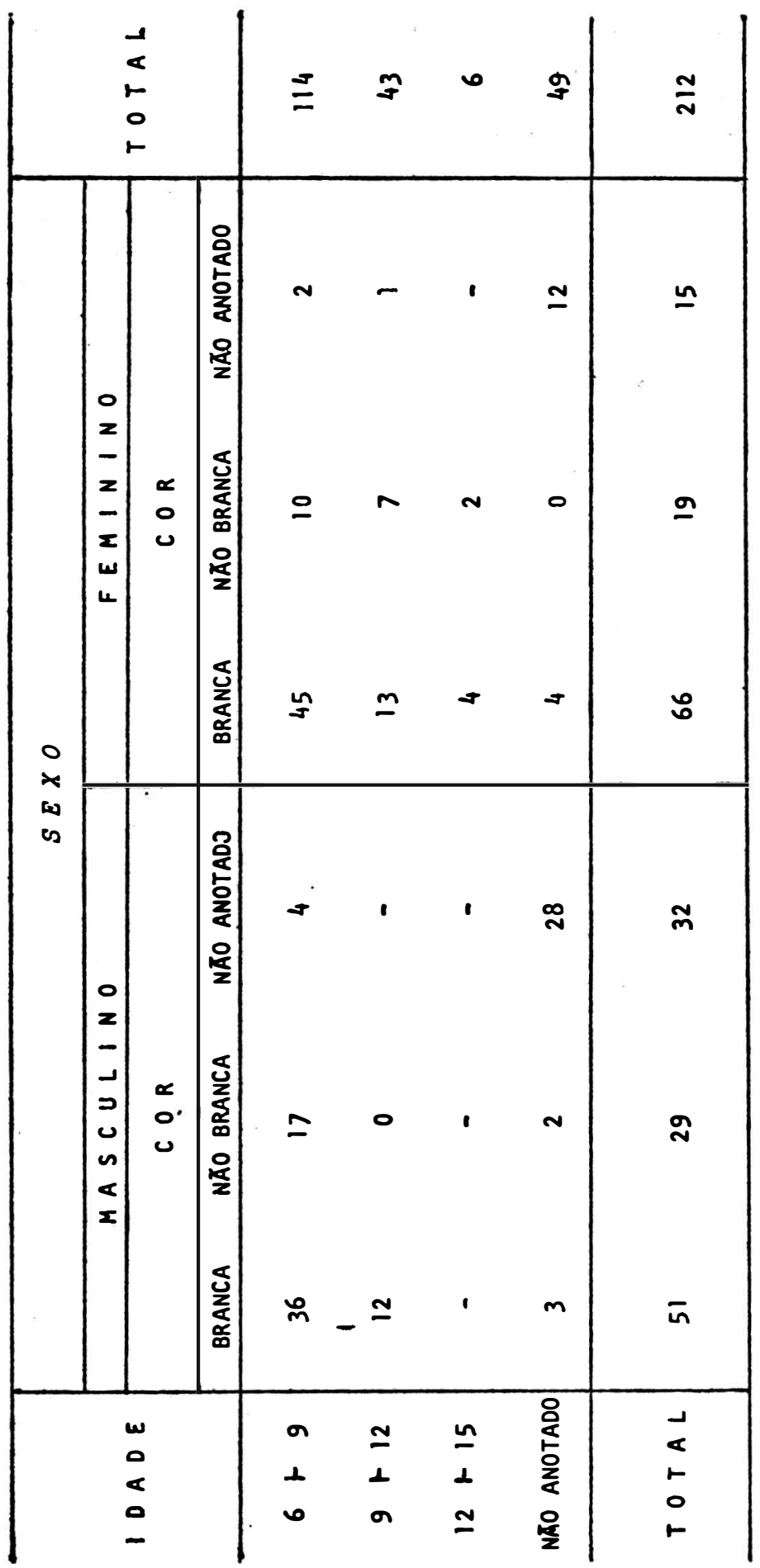



de tuberculose a partir do levantamento tuberculinico. Rev. Bras. Enf.; DF, 29 : 106$114,1976$.

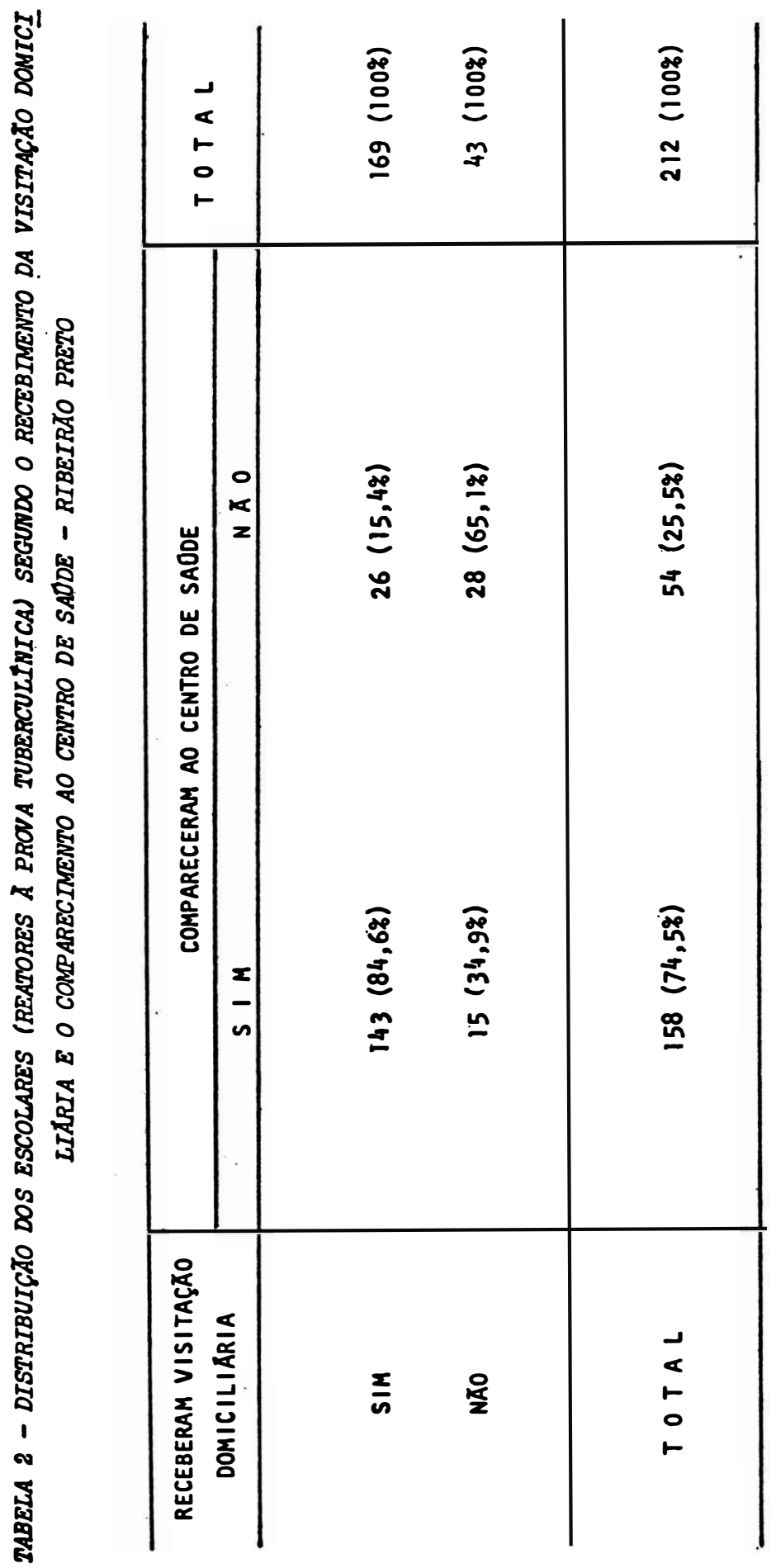




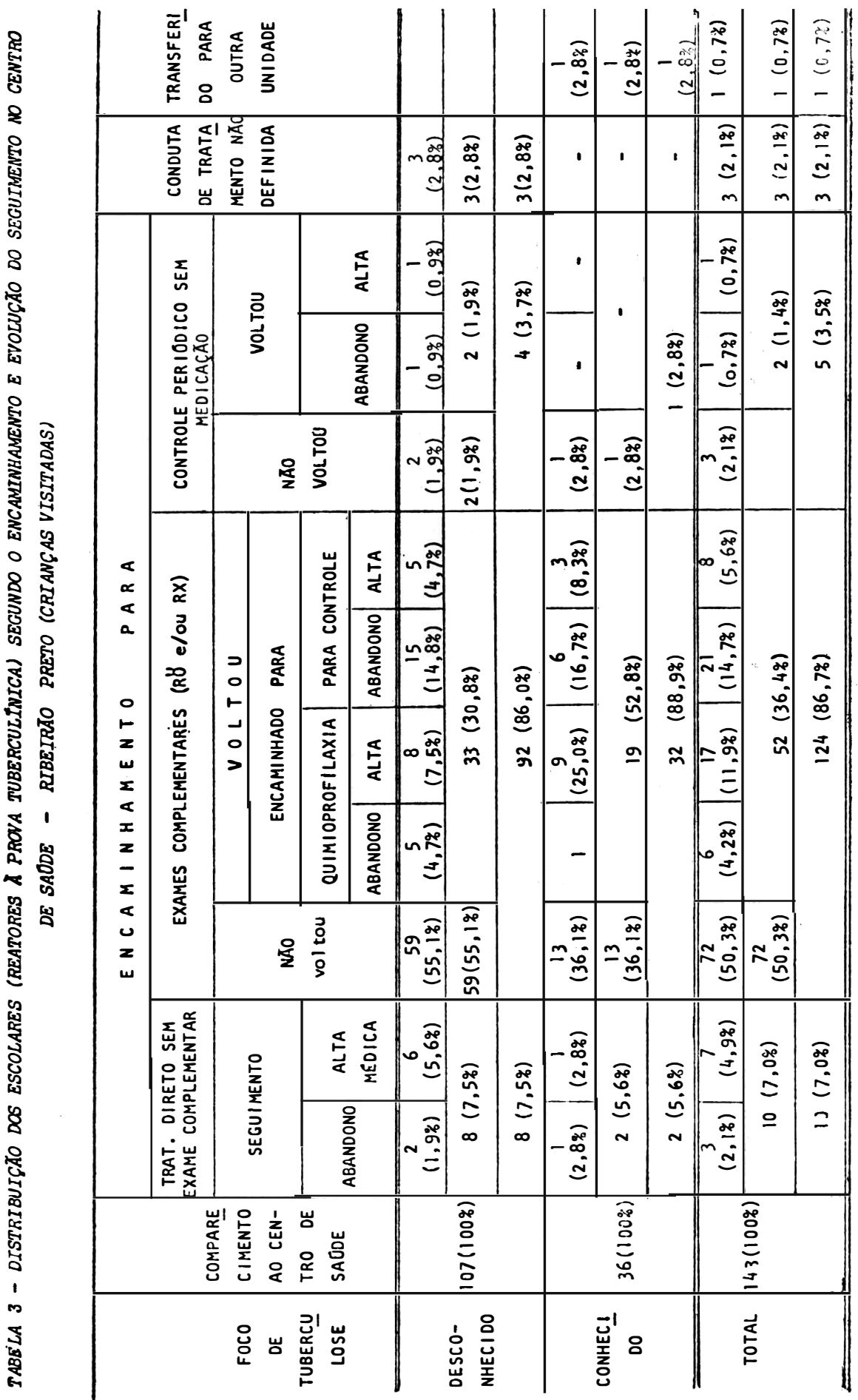




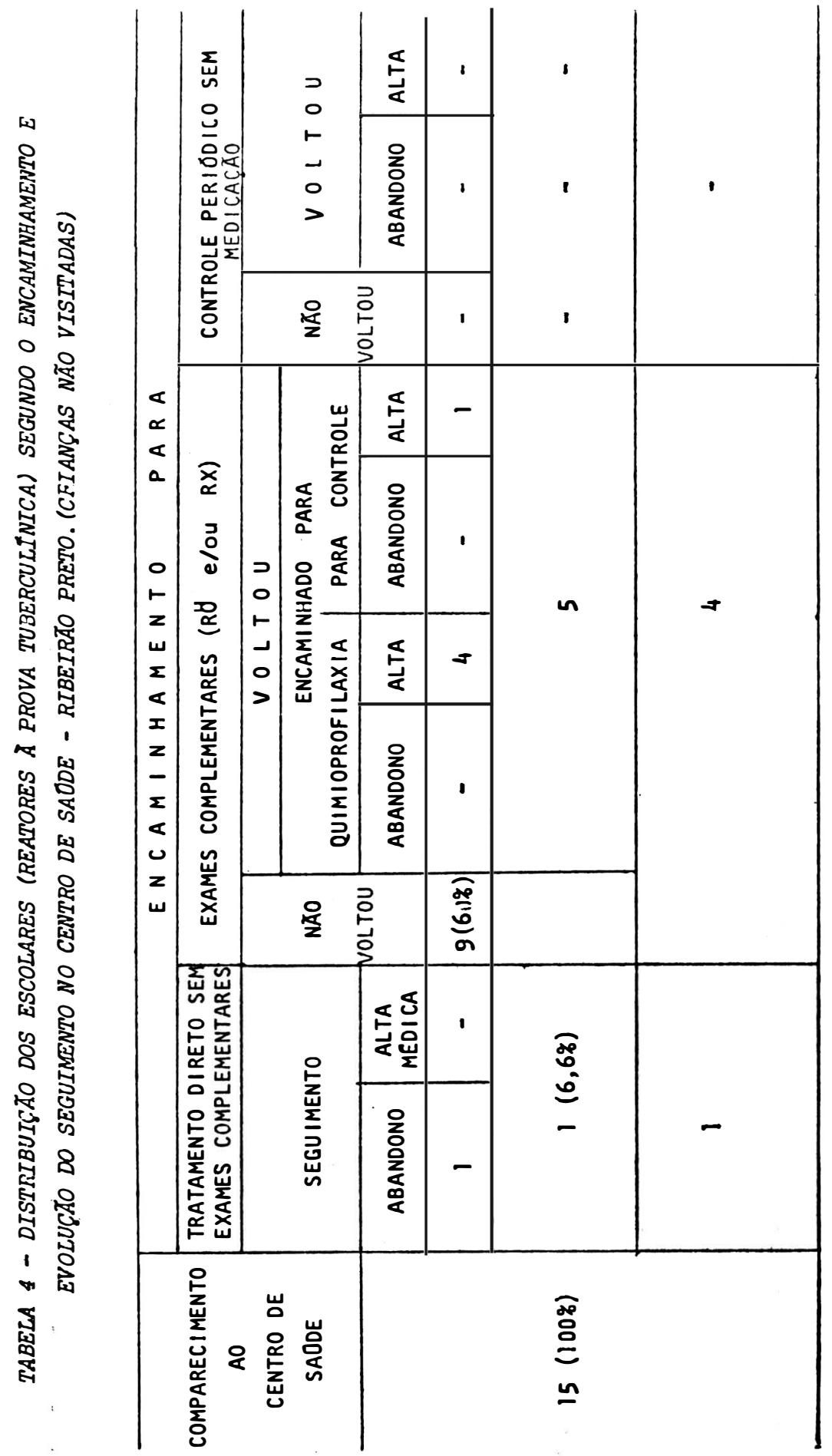


STPAGALI-GOMOS, D.L. e colaboradores - Pesquisa centripeta e operacional de focos de tuberculose a partir do levantamento tuberculinico. Rev. Bras, Enf.; DF, 29 : 106114, 1976.

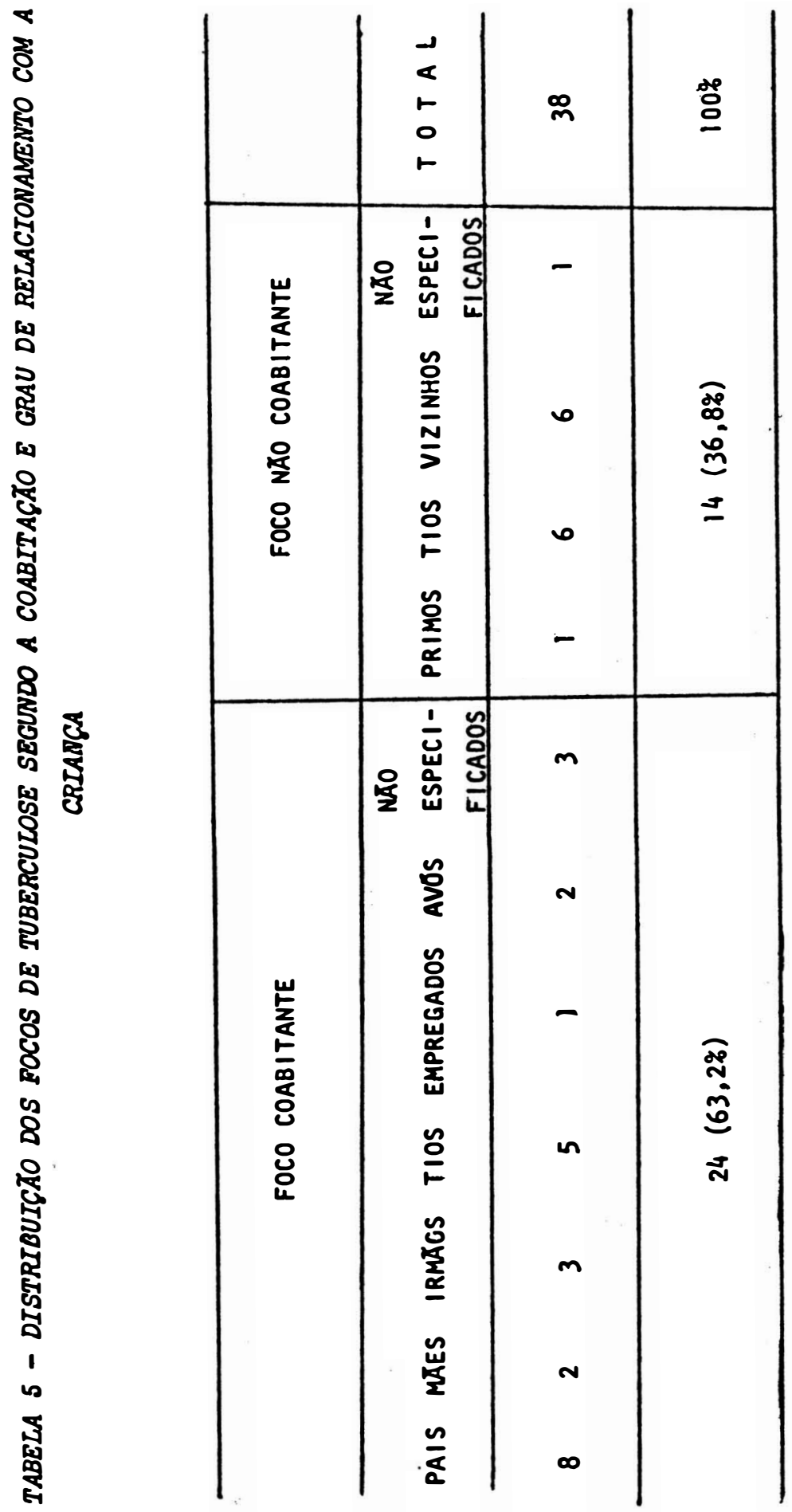

